\title{
Comparing state anxiety and mindfulness between mindfulness and loving-kindness meditation whilst controlling for the effect of altruism and boredom
}

\author{
Iris-Anda Ilies $^{B, C, D, E}$, Helen Egan $\mathbb{1 D}^{D, E}$, Michail Mantzios $\mathbb{( D D}^{A, C, D, E, F}$ \\ Birmingham City University, Birmingham, United Kingdom
}

BACKGROUND

Although it has been determined that mindfulness meditations are positively related to personality constructs such as conscientiousness, there is no clear evidence of whether personality can influence the effectiveness of mindfulness intervention. The aim of the current research was to investigate the immediate effects of single sessions of mindfulness meditation ( $\mathrm{MM}$ ) and loving-kindness meditation (LKM) on state anxiety and state mindfulness and establish whether there is a difference between the outcomes of the two practices. Altruism and boredom were used as covariates to observe whether they have a significant impact on the final results.

\section{PARTICIPANTS AND PROCEDURE}

University students $(N=80)$ were randomly allocated to either the MM or LKM condition and were asked to complete the scales before and after they listened to audio guided meditation instructions. Prior to the meditation participants completed state mindfulness and state anxiety scales. Post-meditation participants again filled in state mindfulness and state anxiety scales, and trait scales on altruism and boredom.

\section{RESULTS}

The results indicated that both types of mindfulness-based practices successfully decreased the initial levels of anxiety and elevated state mindfulness. Non-significant differences between the outcomes of the meditative practices were observed when controlling for altruism and boredom.

\section{CONCLUSIONS}

Alternative practices appeal more to some participants than to others. Clinical implications are discussed with a focus on the beneficial effects of both MM and LKM.

\section{KEY WORDS}

mindfulness; loving-kindness meditation; anxiety; altruism; boredom

Corresponding AUthor - Michail Mantzios, Ph.D., Birmingham City University, The Curzon Building Room C307,

B4 7BD Birmingham, United Kingdom, e-mail: michael.mantzios@bcu.ac.uk

Authors' contribution - A: Study design · B: Data collection · C: Statistical analysis · D: Data interpretation ·

E: Manuscript preparation · F: Literature search · G: Funds collection

to Cite this ARticle - Ilies, I. A., Egan, H., \& Mantzios, M. (2019). Comparing state anxiety and mindfulness between

mindfulness and loving-kindness meditation whilst controlling for the effect of altruism and boredom. Current

Issues in Personality Psychology, 7(2), 109-119.

RECEIVED 20.01.2019 · REVIEWED 15.04.2019 • ACCEPTED 23.04.2019 • PUBLISHED 25.05.2019 


\section{BACKGROUND}

Meditation is a self-regulatory practice that promotes mental and physical wellness whilst decreasing harmful thoughts and/or emotions (Leppma \& Young, 2016). There are multiple purposes of meditation, depending on the processes that it focuses on. Deep relaxation, enhanced compassion towards the self and others, and stress reduction are common intentions for those who engage in these practices (Brisbon \& Lowery, 2011). Within mindfulness-based programmes (e.g., mindfulness-based stress reduction), different kinds of meditation are used, but their effectiveness in increasing mindfulness and decreasing anxiety has not been explored experimentally.

Affective disorders such as anxiety or depression are widely treated through pharmacological approaches and cognitive-behaviour therapies, with studies identifying small to moderate effects in improving these psychological issues (Duijts, Faber, Oldenburg, van Beurden, \& Aaronson, 2011). Given this limited efficacy, the use of alternative psychosocial practices, namely meditation-based interventions, has been suggested as an additional tool for coping with affective disorders (Jacobsen \& Jim, 2008). Mindfulness meditation (MM), initially practiced in Buddhist culture (Edenfield \& Saeed, 2012), has been identified as an efficient treatment for various psychological issues, such as anxiety, stress, and anger (Hayes \& Feldman, 2004; Hofmann, Sawyer, Witt, \& Oh, 2010). MM is believed to prevent or suppress distressing thoughts and emotions associated with anxiety and stress (Keng, Smoski, \& Robins, 2011), and consists of adaptive coping mechanisms, accurate appraisal of stressors (Edenfield \& Saeed, 2012; Garland, 2007), increased awareness of sensations, thoughts, emotions and perceptions (Hofmann, Grossman, \& Hinton, 2011), as well as enhanced compassion and non-judgmental acceptance (Leppma \& Young, 2016).

A narrative review undertaken by Bamber and Schneider (2016) has also supported that view, showing that a multitude of research papers demonstrated that meditation generated significantly lower levels of stress and anxiety. Both studies by Würtzen et al. (2013) and Kim, Kim, Do Ahn, Seo, and Kim (2013) have demonstrated the effectiveness of mindfulnessbased interventions for women who have suffered from breast cancer, suggesting that meditation has, in fact, significantly reduced the anxiety levels of patients. Song and Lindquist's (2015) study also confirmed the efficacy of the intervention, when looking at the effectiveness of mindfulness-based stress reduction in managing depression, anxiety and stress of nursing students. They also noted that an additional advantage is the flexibility and accessibility of meditation, as it can usually be practiced at any time and place. Previous literature determined that brief sessions of MM helped university students develop an increased tolerance to stress, lowered negative mood and anxiety and enhanced state mindfulness (McClintock \& Anderson, 2013; Zeidan, Johnson, Gordon, \& Goolkasian, 2010). Within a clinical population, mindfulness training was found to reduce the correlation between cravings for damaging substances and depressive symptoms (Feldman, Greeson, \& Senville, 2010) and to provide to patients suffering from depression an adaptive coping mechanism against overwhelming emotions (Hofmann et al., 2015).

Additional benefits are the observed changes in personality when practicing MM. Indeed, previous research suggests that there are causal links between mindfulness practice and types of personality. Studies proposed that MM can be associated with reduced worry and negative thoughts, linking to a lower level of neuroticism (Baer, Smith, Hopkins, Krietemeyer, \& Toney, 2006; Brown, Ryan, \& Creswell, 2007). Likewise, the exposure to a wide range of emotions, perceptions and experiences initiated by this intervention could be related to openness, as well as extraversion, referring to an individual's sociability, positive thoughts and emotions, and enjoyment of new adventures (Baer, Smith, \& Allen, 2004). Mindfulness has also been associated with conscientiousness, as individuals who engage in meditation have been documented as having increased levels of selfdiscipline and responsibility (Giluk, 2009). In addition, agreeableness is another trait that is influenced by MM, with sources indicating that meditation improves feelings of compassion, empathy and concern for others (Ashar et al., 2016; Nilsson, 2016). Van den Hurk et al. (2011), however, presented outcomes whereby agreeableness was not influenced by meditation. This finding contradicted other research (as well as the Buddhist theories) which suggested that the practice of meditation reflects greater compassion, warmth and altruism - aspects directly relevant to agreeableness (Boellinghaus, Jones, \& Hutton, 2014). It was proposed that the lack of agreeableness could be interpreted as the absence of "metta meditation" practice (such as loving-kindness meditation), which cultivates characteristics closely related to this trait (van den Hurk et al., 2011).

A meditative technique considered as one of the most prevalent kindness-based interventions is loving-kindness meditation (LKM) which in contrast with MM, is based on developing feelings of compassion and acceptance for the self and others (Galante, Galante, Bekkers, \& Gallacher, 2014). The typical way of practicing LKM is in a seated position, quietly contemplating and focusing on expressing affection and positive emotions towards the self, a loved one, a neutral person, to someone with whom the relationship is complicated, and towards all human beings. This practice is aiming to produce a state of unconditional love, compassion and sympathy (Bankard, 2015), and 
it usually includes the repetition of short phrases, such as "May you be safe", "May you be peaceful", "May you be healthy" (Galante et al., 2014). Studies have produced evidence that showed that individuals who practiced LKM presented higher levels of altruism and increased pro-social behaviour - changes which still existed a few days after the intervention (Hutcherson, Seppala, \& Gross, 2008). Due to its prosocial objectives, it was believed that LKM would be advantageous from a societal point of view, in comparison with other meditative practices that do not offer these kinds of benefits (Leppma \& Young, 2016). Further research discovered that the positive emotions developed though kindness-based meditation can improve personal attributes, such as selfacceptance, self-compassion, mindfulness, as well as relations with others, all of which would then lead to increased wellbeing and lower levels of depressive symptoms (e.g., Fredrickson, Cohn, Coffey, Pek, \& Finkel, 2008). A follow-up study by Cohn and Fredrickson (2010) demonstrated that the resources gained through LKM were still maintained 15 months after the practice. These results provided important evidence of functional neuroplasticity in the circuits underlying positive emotions such as compassion or altruism (Weng et al., 2013).

Despite the large amount of evidence which demonstrated that LKM could have a major positive influence on the human body and mind, there are certain studies which suggested that the practice of lovingbased meditation could also be harmful. Research has shown that there are a number of differences between participants who take part in LKM, with some displaying brain responses associated with positive emotions whilst others do not, in particular individuals with a tendency to ruminate (Boellinghaus et al., 2014). Additionally, during the experimental study conducted by Crane, Jandric, Barnhofer, and Williams (2010), it was found that this intervention generated dysfunctional beliefs that happiness can only be achieved through accomplishing specific goals in life, a type of thinking shown to be related to depression. In other cases, similarly with the points made on mindfulness meditation, personality traits (e.g., self-discipline) can determine the level of engagement with the practice and therefore predict the time spent meditating and the accuracy of the final results (Boellinghaus et al., 2014). A certain degree of empathy and a low tendency to worry and rumination were also factors believed to influence the effectiveness of loving-kindness meditation (Mascaro, Rilling, Negi, \& Raison, 2013). These findings suggest the presence of individual differences and the effect of personality on meditative practices, which has not been explored between LKM and MM.

Two personality traits are explored within this study. First, a construct that appears important in exploring individual differences, especially when considering the differing nature of the practices (MM vs. LKM), is altruism. Altruism has been defined as a motivational state aimed at increasing the welfare of another individual without expecting personal benefits (Lozada, D'Adamo, \& Fuentes, 2011). Research found that altruism has been associated with significant interpersonal outcomes, such as reduced level of aggression, a more compassionate attitude towards stigmatised groups, decreased loneliness and enhanced social connection (Crocker \& Canevello, 2008). Studies suggested that compassion, altruism and empathy could be cultivated through meditation (Wallmark, Safarzadeh, Daukantaite, \& Maddux, 2013), due to greater flexibility in emotion regulation promoted by mindfulness training (Chambers, Gullone, \& Allen, 2009). Flexibility in emotion regulation would then enhance positive emotions towards people who are suffering, as well as pro-social behaviour (Klimecki, Leiberg, Lamm, \& Singer, 2012). Multiple research papers also demonstrated that having altruistic intentions can significantly improve one's health (e.g., Aknin, Dunn, \& Norton, 2012; Lozada et al., 2011). From a biological perspective, it was found that individuals who practice compassion meditation (CM) for an extended period of time can present a greater empathic neural response when they are aware of other people in distress (Weng et al., 2013). This type of intervention was also suggested to strengthen the immune system, improve psychological and physical health and increase life satisfaction (Fredrickson et al., 2008). Although it has been proposed in the literature that compassion meditation might have an impact on certain areas of the brain involving affect regulation, Davidson and McEwen (2012) suggested that there is no clear proof that compassion or other personality attributes could be modified in any way through this practice. Whilst MM focuses more on one's general experience and acceptance of the present moment, CM and LKM are directed towards the self and others and they involve the intention of supporting and caring for those who are suffering (Boellinghaus et al., 2014). All in all, there is a clear association between altruism and the wellbeing of individuals, as well as the positive impact it can have on society as a whole. Moreover, although there is evidence confirming the influence that meditation can have on the levels of altruism (Wallmark et al., 2013), there are little to no studies investigating whether altruism or lack thereof could alter the outcomes of this type of practice. Due to these factors, it is important to further explore this construct and observe whether being more altruistic enhances or weakens the outcomes of LKM, especially when compared to MM.

Second, judging by the general trend of feeling bored when teaching novices to meditate, boredom thresholds may be more influential than believed in contemporary contemplative research. Boredom 
is usually formed by lack of stimulation or physiological arousal and unpleasant emotions, and it could be induced by objects or events that do not present meaningful values (Goetz, Frenzel, Pekrun, \& Hall, 2006). Although boredom has not received as much attention from researchers as other emotions such as anger, joy or anxiety, it has been found to be related to a range of issues, such as alcohol and nicotine consumption, drug use (LePera, 2011), delinquency, stress, dissatisfaction with life and other health problems (Pekrun, Goetz, Daniels, Stupnisky, \& Perry, 2010). In addition, performance has been seen as greatly affected by the level of boredom, as it could impact on the motivation and effort needed to perform a task, as well as cognitive resources, such as attention or memory (Pekrun et al., 2010). The level of boredom would then influence the efficiency of meditation as studies discovered that a major difference in intervention outcomes could be made by the level of knowledge and training possessed by the individual (Hutcherson et al., 2008). The Buddhist assumption is that a considerable amount of time is needed in order to develop the abilities practiced during meditation (Grossman et al., 2010). Thus practitioners who have been involved in MM or LKM for a long time would show different results in comparison to novices (Hofmann et al., 2011; Lutz et al., 2009). This would also be the case with regard to the intensity of loving-kindness meditation, where expert practitioners consider it more helpful during stressful situations, whilst beginners find it more difficult (Bankard, 2015). Furthermore, Wittmann and Paulus (2008) also found that high boredom-prone individuals would overestimate the duration of a certain task, compared to low boredom-prone individuals, and they were more likely to perceive the situation as non-challenging and monotonous. As a result of this, individuals who feel bored when practicing meditation would be less likely to engage in the practice in an open and dedicated manner, leading to inefficient outcomes. Considering the significant impact that the presence of boredom can have on the effectiveness of meditation, a factor which represents the main variable of the current paper, this construct will be used as a second covariate. Finally, an additional motive for introducing boredom as a variable in the current experimental study is the limited literature exploring the influence of boredom amongst two types of meditation and their effects on levels of anxiety and mindfulness.

Due to the small number of studies regarding meditation-based interventions, the present study investigated the effects of two types of meditative practices (MM and LKM) on state anxiety and mindfulness amongst university students. The aim of the research was to discover whether there is a difference between the outcomes of these practices and whether higher altruism could influence the results of the practices, especially in the LKM condition. As research suggested that the level of boredom could have an important impact on performance and engagement (Pekrun et al., 2010; Zakay, 2014), boredom was also used as a covariate. Based on previous literature, it was expected that the participants who would practice MM and LKM would score significantly higher in mindfulness and lower in anxiety when exploring pre- and post-practice results. However, participants' altruism might improve the results for LKM in comparison to the MM condition. Additionally, participants who scored high in boredom would be expected to display little to no changes after the brief session of meditation, whilst individuals with low scores of boredom would be hypothesized to present significant differences before and after practices.

\section{PARTICIPANTS AND PROCEDURE}

\section{PARTICIPANTS}

The participants taking part in the current study were a self-selected sample of 80 university students (66 females and 14 males), randomly allocated to a Mindfulness Meditation group $(n=40)$ and a Loving-kindness Meditation group $(n=40)$. They were from a variety of cultural backgrounds, the majority being White/White British $(n=60)$ and the rest Asian/ Asian British $(n=10)$, Black/Black British $(n=4)$ and Mixed $(n=6)$, with the age range between 18 and 51 years old $(M=22.48, S D=5.81)$. With regard to previous training, 17 participants indicated that they had practiced or currently practiced meditation, with the remaining 63 participants never having engaged in this type of practice. Participants were students of a UK university and they volunteered to take part in the experiment using the university's Research Participation Scheme in exchange for university credits.

\section{MATERIALS}

The Self Report Altruism Scale (Rushton, Chrisjohn, \& Fekken, 1981) consisted of 20 items (e.g., "I have given money to a charity", "I have offered to help a handicapped or elderly stranger across a street") and was used to measure pro-social behaviour performed with altruistic intentions. The questionnaire consisted of four subscales, measuring the public, social, charity and support types of altruistic aspects. A Likert-type scale was used, with five points, varying from never to very often. The Cronbach's $\alpha$ of the altruism scale in the current study was .87 .

The State Anxiety Inventory (Marteau \& Bekker, 1992) included six items (e.g., "I feel calm", "I am worried") and it was developed to identify the level of 
state anxiety possessed by individuals. Each item was measured using four points, ranging from 1 (not at all) to 4 (very much). In the present study, $\alpha$ was .83 before and .85 after practice. State Mindfulness Scale (Tanay \& Bernstein, 2013) with 21 items (e.g., "I was aware of different emotions that arose in me", "I felt in contact with my body") which measured the state of mindfulness, including reflection and awareness of bodily sensations, mental events and environment. The scale involved five points, ranging from 1 (not at all) to 5 (very well). The pre- and post-practice $\alpha$ in the current study was .96 and .94, respectively.

The State Boredom Scale (Fahlman, Mercer-Lynn, Flora, \& Eastwood, 2013) has been used for debriefing and consists of 29 items (e.g., "Time is passing by slower than usual", "My mind is wandering"). This questionnaire measured state boredom, along with feelings of depression and anxiety, anger, impulsivity and life satisfaction. This scale had seven points, varying from 1 (strongly disagree) to 7 (strongly agree). The Cronbach's $\alpha$ in the current study was .95 .

Audio recordings with approximately 12 minutes of guided meditation (MM and LKM) were used during the experiment. Audio recordings were developed by the last author, who has been practicing and teaching MM for 12 years. Headphones were used to eliminate any external distractions, and computers to display the questionnaires.

\section{PROCEDURE}

The present study was conducted in a quiet laboratory inside the university. All participants were briefed about the topic of the experiment and ethical considerations. Each of them received an Information Sheet stating that the participation in the research study was completely voluntary and they had the right to withdraw at any time, with no explanation needed. Participants were also informed that their answers would be anonymous and confidential and their identity would not be revealed. The information sheet also described the lack of disadvantages or risks of taking part in the study, except for the possible slight discomfort due to the emotional nature of some of the statements included in the self-reported anxiety questionnaire. Participants were also given a Consent Form where they confirmed that they acknowledged the information presented and they agreed to take part in the study.

Participants were randomly allocated to either practice of mindfulness meditation or loving-kindness meditation, each audio recording lasting for about 12 minutes. Every participant was instructed to use the headphones provided while listening to the guided instructions which were presenting either a breathing meditation or a loving-kindness technique. They all completed self-reported ques- tionnaires on state mindfulness and state anxiety before and after they had listened to one of the two audio-taped guided meditation instructions. Participants also completed a self-reported questionnaire on altruism (which served as a covariate) before the practices and a state boredom questionnaire after the meditation. Moreover, every session was formed of groups of between three and six participants who listened to the guided meditation simultaneously.

\section{DATA ANALYSIS}

Initially, a mixed subjects 2 (meditation type: mindfulness meditation; loving-kindness meditation) $\times 2$ (time: pre-, post-meditation) ANOVA design was employed for mindfulness and anxiety. Another mixed subjects 2 (meditation type: mindfulness meditation; loving-kindness meditation) $\times 2$ (time: pre-, postmeditation) ANCOVA design was employed for mindfulness and anxiety, whilst controlling for the variance of altruism and boredom. Power analysis for a mixed model ANCOVA with 2 groups and 2 levels was conducted with $G^{*}$ Power to determine a sufficient sample size at an alpha level of .05, a power of .80 , a correlation of .50 between the pre- and postpractice measurements, and a medium effect size $(f=.25)$. Based on the aforementioned assumptions, the desired sample size was 34 . Considering the potential loss of participants, we aimed at 40 to ensure that even a reduction in sample size would ensure a medium effect size.

\section{RESULTS}

LKM and MM were tested through independent sample $t$-tests for differences in baseline state mindfulness, state anxiety, and age. For age, the results revealed that the groups did not significantly differ, $t(78)=1.04, p=.301$, and this was also true for baseline state mindfulness, $t(78)=-0.39, p=.694$, and state anxiety $t(78)=0.25, p=.803$. Tables 1 and 2 present the effects of the type of practice (LKM or $\mathrm{MM}$ ) on anxiety and mindfulness, before and after the practice. It can be observed in Table 1 that the initial scores for mindfulness for the group who listened to loving-kindness meditation $(M=59.55$, $S D=16.96)$ and mindfulness meditation $(M=61.20$, $S D=20.32)$ improved after both practices were administered (LKM: $M=80.73, S D=15.97$; MM: $M=77.05, S D=16.41)$, with the total scores increasing from $M=60.32, S D=18.61$ to $M=78.89$, $S D=16.19$. These results indicated that mindfulness meditation, as well as loving-kindness meditation, has a positive effect on state mindfulness, with LKM showing a slightly better improvement. Parametric assumptions were met. 
Table 1

Means and standard deviations for the state mindfulness scores, before and after the intervention

\begin{tabular}{lccc}
\hline & Condition & $M$ & $S D$ \\
\hline Pre-measurement & LKM & 59.55 & 16.95 \\
mindfulness & MM & 61.20 & 20.31 \\
Post-measurement & LKM & 80.73 & 15.97 \\
mindfulness & MM & 77.05 & 16.40 \\
\hline
\end{tabular}

Note. LKM - loving-kindness meditation, MM - mindfulness meditation.

Table 2

Means and standard deviations for the state anxiety scores, before and after the intervention

\begin{tabular}{lccc}
\hline & Condition & M & $S D$ \\
\hline Pre-measurement & LKM & 11.30 & 3.30 \\
anxiety & MM & 11.78 & 3.82 \\
Post-measurement & LKM & 8.47 & 2.62 \\
anxiety & MM & 8.92 & 3.25 \\
\hline
\end{tabular}

Note. LKM - loving-kindness meditation, MM - mindfulness meditation.

Table 2 also shows an improvement after the practice, this time the lower scores of anxiety displaying a positive impact as a result of the meditative practice. It can be seen that the anxiety scores for the LKM condition $(M=11.30, S D=3.30)$ decreased after the practice was applied $(M=8.47, S D=2.62)$. Similarly, the initial scores within the MM group decreased from $M=11.78, S D=3.82$ to $M=8.92, S D=3.25$. The difference between pre- $(M=11.54, S D=3.55)$ and post-practice results $(M=8.70, S D=2.94)$ can also be noted in the total scores. Therefore, it is concluded that MM and LKM have an important influence on state anxiety.

To analyse these scores further, a 2 (meditation type: mindfulness meditation; loving-kindness meditation) by 2 (time: pre-, post-practice) mixed measures ANOVA design was carried out, with time as a repeated measures factor and meditation type as a between-subjects factor for state mindfulness and state anxiety.

There was a significant main effect of time for state mindfulness scores $F(1,78)=70.57, p<.001$, $\eta^{\mathrm{p}}{ }_{2}=.48$, indicating a change in levels of state mindfulness after the practice. Forty-eight percent of the variance in state mindfulness was accounted for by time. There was also a main effect of meditation type (LKM or MM) which was not statistically significant, $F(1,78)=0.10, p=.755$, indicating that the scores for state mindfulness were not greatly influenced by the type of practice. Additionally, the interaction between the time of administering the state mindfulness scale and the type of meditation was also not significant, $F(1,78)=1.46, p=.231$.

The main effect for state anxiety scores was statistically significant, $F(1,78)=71.68, p<.001, \eta^{\mathrm{p}}{ }_{2}=.48$, suggesting that the practice had an impact on the state anxiety levels after the meditative practice. A percentage of $48 \%$ of the variance in state anxiety scores was accounted for by the time of practice. In contrast, the main effect for meditation type was not significant, $F(1,78)=0.51, p=.479$, indicating that the scores for state anxiety were not greatly influenced by the type of practice (MM or LKM). In addition, the relationship between the time when the state anxiety scales were completed (before or after practice) and the type of meditation was not significant as well, $F(1,78)=0.001, p=.970$.

The results showed that scores for state anxiety and state mindfulness improved after the practice but the type of meditation did not make a difference in the final outcome.

Furthermore, a mixed subjects 2 (meditation type: mindfulness meditation; loving-kindness meditation) $\times 2$ (time: pre-, post-meditation) ANCOVA design was employed for mindfulness and anxiety. The independent variable was represented by the type of practice (mindfulness or loving-kindness meditation) and the dependent variable represented by the results of the state anxiety and state mindfulness scales. The covariates in this analysis were the scores for self-reported altruism scale which was administered before the practices and scores for the boredom scale which was tested after the practices.

With regard to the influence of altruism on state anxiety scores, it can be noted that there was no significant difference between the type of meditation and altruism after adjusting for the respective covariate, $F(1,77)=0.003, p=.956$. Additionally, there was no relationship between altruism scores and state anxiety scores, $F(1,77)=0.42, p=.518$. Moreover, no significant difference was found between the type of mediation and boredom after adjusting for state boredom, $F(1,77)=0.08, p=.781$, and the relationship between state anxiety and boredom scores was also not significant, $F(1,77)=0.48, p=.490$. The findings suggested that state anxiety scores were not affected by the administration of either altruism or boredom scales.

The administration of covariates was also applicable to state mindfulness scores. The influence of altruism on the type of meditation was similar as in the previous case, as there was not a significant relationship between the two variables $F(1,77)=1.46$, $p=.230$. The difference between the levels of altruism and state mindfulness scores was not significant as well, $F(1,77)=0.08, p=.774$. In addition to that, there was no significant association between the type of meditation and boredom, $F(1,77)=0.14, p=.709$, and 
state mindfulness scores were not influenced by the levels of boredom as there was no significant relationship between the two, $F(1,77)=2.52, p=.117$. Overall, it is clear that boredom and altruism did not have an important impact on the final scores for state mindfulness.

\section{DISCUSSION}

The current research aimed to establish whether two different meditation practices (mindfulness meditation and loving-kindness meditation) presented distinct outcomes when investigating state anxiety and mindfulness. The study also incorporated altruism and boredom as covariates to identify whether they might influence the outcomes. The findings demonstrated that participants showed a decrease in state anxiety levels and elevated levels of state mindfulness after the practice was administered, with no significant differences between the types of meditation. Moreover, although it was predicted that the participants with higher levels of altruism would show better results after listening to guided loving-kindness meditation, the findings demonstrated that the level of altruism as a personality trait did not have an impact on the effectiveness of the practices. Similarly, the effects of meditation on state anxiety and state mindfulness were not impaired by the levels of boredom presented by participants.

This outcome is consistent with previous research that suggested that meditation-based interventions have the ability to significantly reduce psychological distress and anxiety and increase mindfulness (Feldman et al., 2010). Mindfulness meditation includes learning how to become more aware and less judgmental of thoughts, emotions and experiences as they occur in the present moment and acknowledge and recognize them as temporary and subjective perceptions (Keng et al., 2011). In this way, individuals automatically become more mindful of their inner cognitions and beliefs as well as their external behaviour and environment but also more accepting and patient with themselves, which would lead to less stress and emotional turmoil (van den Hurk et al., 2011). It could be suggested that the decreased psychological distress and better ability in regulation of emotions represent a similarity between the effects of MM and LKM, an aspect which would play an important role in the outcomes of the current study. The audio recording of mindfulness meditation listened to by participants included elements of mindful breathing, awareness of the body and the mind and enhanced focus on the present moment.

Similarly, loving-kindness meditation is based on cultivating emotions of unconditional love, compassion, harmony and peace towards the self and others (Hofmann et al., 2011). Additionally, LKM has been reported to enhance resilience, self-esteem and social connectedness and decrease negative affect, including anxiety or depression, through providing training of compassion and kindness towards the self (Leppma \& Young, 2016). State mindfulness has also been found to be strongly correlated with the practice of loving-kindness meditation, due to application of positive affect, acceptance and openness (May, Weyker, Spengel, Finkler, \& Hendrix, 2014). The LKM audio recording listened to by participants during the current study involved relaxation and self-awareness of the body and the mind, leading on to cultivating feelings of kindness and compassion for the self and a loved one, an acquaintance, an undesirable or controversial figure, and all beings through the repetition of phrases, such as "may you be safe" or "may you be peaceful". It could be proposed that by being mindful of the feelings and words spoken, as well as challenging the wandering mind and strengthening the focus on the present activity, the LKM practice possessed elements that could explain the current findings.

Clearly, both loving-kindness meditation and mindfulness meditation proved to have a similar impact on state anxiety and state mindfulness regardless of the amount of dissimilarities between them. One explanation for the comparable influence that MM and LKM have on state mindfulness and state anxiety would be the close association between self-compassion and mindfulness, the main characteristics related to loving-kindness meditation and mindfulness meditation, respectively (Boellinghaus et al., 2014). Studies have indicated that changes in mindfulness are linked to changes in brain areas believed to be involved in pro-social behaviour and kindness and compassion is created in an atmosphere of openness to experience, acceptance and appreciation (Tirch, 2010). Additionally, loving-kindness meditation has been associated with the construct of mindfulness by providing individuals with helpful tools in combating negative feelings towards the self and others and cultivating a healthier sense of self (Analayo, 2010). It would be expected that the separation from difficult emotions would then lead to a higher acceptance and openness towards existing in the present moment, with no judgment or criticism, an element linked to state mindfulness and MM. Therefore, it could be assumed that MM and LKM are interconnected regarding their effect on certain psychological aspects, and this may possibly explain the unexpected impact that both practices had on state mindfulness. Similarly, the findings could be explained through the state mindfulness scale and its items, which fit both MM and LKM meditation contents. For example, "I noticed emotions come and go" and "I noticed pleasant and unpleasant emotions" could be part of both meditations, although the way and purpose of "noticing" may be different between practices. 
The second hypothesis could not be demonstrated as the level of altruism reported by participants did not influence the final results. One explanation for these findings may be the gender difference within the sample of the study, as there were significantly more females $(n=66)$ than males $(n=14)$. However, previous research has not provided enough evidence regarding the difference between females and males and altruistic behaviour (Visser \& Roelofs, 2011); thus it is difficult to propose that this would be the main explanation for the lack of interaction. Another plausible factor could be the point mentioned previously, namely the interconnection between LKM and MM and the presence of compassion in both practices. As altruism is a construct which involves a warm attitude and kindness (Rachlin \& Locey, 2011) and these are features also found within MM (Wallmark et al., 2013), it would be understandable why the presence of altruism would not have a significant difference. Future research could involve similar studies, analysing the different impact of MM and LKM on anxiety and mindfulness, but utilise other personality components as covariates, such as self-compassion, aggression or loneliness. It would be predicted that individuals with higher levels of aggression or loneliness would display more positive results after practicing LKM; this would be due to the social nature of this meditative practice, which focuses not only on projecting compassionate emotions towards the self but especially towards others (Bankard, 2015). The findings also showed that the level of boredom felt by participants did not impact on the final scores either. That could be seen as an advantage as it showed that despite the majority of participants being novices, they did not present significant signs of disinterest or fatigue. Research suggested that it is often possible that people who have not practiced meditation before might experience feelings of boredom or restlessness and doubts due to the unfamiliarity of the situation (Fredrickson et al., 2008); however, that was not the case in the current study.

In the current research, we identified four limitations that could be addressed in future research. Firstly, the data collected concerned students only, which makes it difficult to generalise the findings to a larger population. Consequently, the levels of anxiety and ability to focus on the present and be mindful might have been affected by potential academic stressors, such as assignments or exams. Secondly, the disproportion between the number of males and females could also be considered a limitation. However, as it was previously suggested, future research could view this as an opportunity to conduct a comparative study between LKM and MM using an equal number of males and females and observe whether they react differently at these particular practices. Third, the study included a single session of guided meditation which lasted for approximately 12 minutes.
Future research could determine whether the impact of MM and LKM on anxiety and mindfulness differs in terms of their effectiveness over a longer period of time of regular meditative practice. Indeed, there is contrasting evidence as to whether the time spent meditating has a real impact on the final outcome. In a study by Fredrickson et al. (2008) they suggested that the amount of time spent practicing meditation was a meaningful predictor of positive thoughts and feelings, whilst other scientists identified that there is no significant relationship between the quantity of meditation practice and improvement in psychological or physiological measures (Davidson et al., 2003; Shapiro, Brown, \& Biegel, 2007). Fourth, the majority of participants randomized to either LKM or MM were beginners, and studies have proposed that there is a considerable comparison between novices and experts (Hofmann et al., 2011); people who have been practicing meditation for a prolonged period of time showed enhanced performance after the practice, in comparison with novices (Bankard, 2015). The difference between novices and experts might also come into consideration in regards to self-reported questionnaires for assessing mindfulness, as beginners might not fully understand all items (see Grossman \& Van Dam, 2011), while understanding the items may also create some bias in such experiments. Nevertheless, the present limitations do not weaken the research in showing that LKM and MM are equally efficient practices in diminishing the levels of anxiety and elevate state mindfulness.

Regarding the important implications of the current research, the findings suggest that clinical populations such as individuals suffering from affective disorders may equally benefit from both mindfulness and loving-kindness meditation to reduce anxiety; however, future research should replicate the findings to draw clear conclusions. Moreover, MM as well as LKM could be used for educational purposes and be applied in schools or universities as a technique to decrease anxiety and stress, especially during exam periods, but also for overall improved academic performance (Bamber \& Schneider, 2016). A question which has not been answered by the current study and could be investigated by future research is whether individual differences made a difference in the impact of MM and LKM on anxiety and mindfulness. Although it has been determined that mindfulness meditation is positively related to openness and conscientiousness and negatively associated with neuroticism (van den Hurk et al., 2011), there is no certain evidence of whether personality can influence the effectiveness of the meditative practice. Furthermore, previous literature proposed that the format and space where meditation takes place should also be taken into account, as extraverted individuals may be more responsive during group practice, whilst introverts may feel intimidated or anxious in 
a group setting and prefer individual training (Wahbeh, Lane, Goodrich, Miller, \& Oken, 2014).

\section{CONCLUSIONS}

The current research suggests that mindfulness meditation and loving-kindness meditation share similar abilities with regard to lowering levels of anxiety and increasing state mindfulness. The findings have also raised questions for future research about the impact of personality in the effect of LKM and MM on anxiety and mindfulness, in particular about the role of altruism and its association with these practices, especially when considering traits such as compassion or aggression. Additionally, this outcome offered alternative methods for decreasing state anxiety which may be used both in clinical and non-clinical contexts. The effects of meditation and connection to personality traits may offer further ways to enhance commitment and engagement in specific practices to enhance health and wellbeing.

\section{RefERENCES}

Aknin, L. B., Dunn, E. W., \& Norton, M. I. (2012). Happiness runs in a circular motion: Evidence for a positive feedback loop between prosocial spending and happiness. Journal of Happiness Studies, 13, 347-355. https://doi.org/10.1007/s10902-011-9267-5

Analayo, B. (2010). Satipațthāna: The direct path to realization. Cambridge, United Kingdom: Windhorse.

Ashar, Y. K., Andrews-Hanna, J. R., Yarkoni, T., Sills, J., Halifax, J., Dimidjian, S., \& Wager, T. D. (2016). Effects of compassion meditation on a psychological model of charitable donation. Emotion, 16, 691-705. https://doi.org/10.1037/emo0000119

Baer, R. A., Smith, G. T., \& Allen, K. B. (2004). Assessment of mindfulness by self-report: The Kentucky Inventory of Mindfulness Skills. Assessment, 11, 191-206. https://doi.org/10.1177/1073191104268029

Baer, R. A., Smith, G. T., Hopkins, J., Krietemeyer, J., \& Toney, L. (2006). Using self-report assessment methods to explore facets of mindfulness. Assessment, 13, 27-45. https://doi.org/10.1177/1073191105283504

Bamber, M. D., \& Schneider, J. K. (2016). Mindfulness-based meditation to decrease stress and anxiety in college students: a narrative synthesis of the research. Educational Research Review, 18, 1-32. https://doi.org/10.1016/j.edurev.2015.12.004

Bankard, J. (2015). Training Emotion Cultivates Morality: How Loving-Kindness Meditation Hones Compassion and Increases Prosocial Behavior. Journal of Religion and Health, 54, 2324-2343. https://doi.org/10.1007/s10943-014-9999-8

Brisbon, N. M., \& Lowery, G. A. (2011). Mindfulness and levels of stress: a comparison of beginner and advanced hatha yoga practitioners. Journal of Religion and Health, 50, 931-941. https://doi. org/10.1007/s10943-009-9305-3

Boellinghaus, I., Jones, F. W., \& Hutton, J. (2014). The role of mindfulness and loving-kindness meditation in cultivating self-compassion and otherfocused concern in health care professionals. Mindfulness, 5, 129-138. https://doi.org/10.1007/ s12671-012-0158-6

Brown, K.W., Ryan, R. M., \& Creswell, J. D. (2007). Mindfulness: Theoretical foundations and evidence for its salutary effects. Psychological Inquiry, 18, 211237. https://doi.org/10.1080/10478400701598298

Chambers, R., Gullone, E., \& Allen, N. B. (2009). Mindful emotion regulation: An integrative review. Clinical Psychology Review, 29, 560-572. https://doi. org/10.1016/j.cpr.2009.06.005

Cohn, M. A., \& Fredrickson, B. L. (2010). In search of durable positive psychology interventions: Predictors and consequences of long-term positive behavior change. The Journal of Positive Psychology, 5, 355366. https://doi.org/10.1080/17439760.2010.508883

Crane, C., Jandric, D., Barnhofer, T., \& Williams, J. M. G. (2010). Dispositional mindfulness, meditation, and conditional goal setting. Mindfulness, 1, 204-214. https://doi.org/10.1007/s12671-010-0029-y

Crocker, J., \& Canevello, A. (2008). Creating and undermining social support in communal relationships: the role of compassionate and self-image goals. Journal of Personality and Social Psychology, 95, 555575. https://doi.org/10.1037/0022-3514.95.3.555

Davidson, R. J., Kabat-Zinn, J., Schumacher, J., Rosenkranz, M., Muller, D., Santorelli, S. F., Urbanowski, F., Harrington, A., Bonus, K., \& Sheridan, J. F. (2003). Alterations in brain and immune function produced by mindfulness meditation. Psychosomatic Medicine, 65, 564-570. https://doi.org/10.1097/01. PSY.0000077505.67574.E3

Davidson, R. J., \& McEwen, B. S. (2012). Social influences on neuroplasticity: stress and interventions to promote well-being. Nature Neuroscience, 15, 689-695. https://doi.org/10.1038/nn.3093

Duijts, S. F. A., Faber, M. M., Oldenburg, H. S. A., van Beurden, M., \& Aaronson, N. K. (2011). Effectiveness of behavioral techniques and physical exercise on psychosocial functioning and healthrelated quality of life in breast cancer patients and survivors a meta-analysis. Psychooncology, 20, 115-26. https://doi.org/10.1002/pon. 1728

Edenfield, T. M., \& Saeed, S. A. (2012). An update on mindfulness meditation as a self-help treatment for anxiety and depression. Psychology Research and Behavior Management, 5, 131-141. Retrieved from http://hdl.handle.net/10342/5804

Fahlman, S. A., Mercer-Lynn, K. B., Flora, D. B., \& Eastwood, J. D. (2013). Development and validation of the Multidimensional State Boredom Scale. Assessment, 20, 68-85. https://doi.org/10.1177/1073191111421303 
Feldman, G., Greeson, J., \& Senville, J. (2010). Differential effects of mindful breathing, progressive muscle relaxation, and loving-kindness meditation on decentering and negative reactions to repetitive thoughts. Behaviour Research and Therapy, 48, 10021011. https://doi.org/10.1016/j.brat.2010.06.006

Fredrickson, B. L., Cohn, M. A., Coffey, K. A., Pek, J., \& Finkel, S. M. (2008). Open hearts build lives: positive emotions, induced through loving-kindness meditation, build consequential personal resources. Journal of Personality and Social Psychology, 95, 1045-1062. https://doi.org/10.1037/a0013262

Galante, J., Galante, I., Bekkers, M. J., \& Gallacher, J. (2014). Effect of kindness-based meditation on health and well-being: a systematic review and meta-analysis. Journal of Consulting and Clinical Psychology, 82, 1101-1114. https://doi.org/10.1037/ a0037249

Garland, E. L. (2007). The meaning of mindfulness: a second-order cybernetics of stress, metacognition, and coping. Complement Health Practice Review, 12, 15-30. https://doi.org/10.1177/1533210107301740

Giluk, T. L. (2009). Mindfulness, big five personality, and affect: A meta-analysis. Personality and Individual Differences, 47, 805-811. https://doi.org/10.1016/j. paid.2009.06.026

Goetz, T., Frenzel, A. C., Pekrun, R., \& Hall, N. C. (2006). The domain specificity of academic emotional experiences. The Journal of Experimental Education, 75, 5-29. https://doi.org/10.3200/JEXE. 75.1.5-29

Grossman, P., Kappos, L., Gensicke, H., D’Souza, M., Mohr, D. C., Penner, I. K., \& Steiner, C. (2010). MS quality of life, depression, and fatigue improve after mindfulness training: A randomized trial. Neurology, 75, 1141-1149. https://doi.org/10.1212/ WNL.0b013e3181f4d80d

Grossman, P., \& Van Dam, N. T. (2011). Mindfulness, by any other name...: trials and tribulations of sati in western psychology and science. Contemporary Buddhism, 12, 219-239. https://doi.org/10.1080/146 39947.2011.564841

Hayes, A. M., \& Feldman, G. (2004). Clarifying the construct of mindfulness in the context of emotion regulation and the process of change in therapy. Clinical Psychology: Science and Practice, 11, 255-262. https://doi.org/10.1093/clipsy.bph080

Hofmann, S. G., Grossman, P., \& Hinton, D. E. (2011). Loving-kindness and compassion meditation: Potential for psychological interventions. Clinical Psychology Review, 31, 1126-1132. https://doi. org/10.1016/j.cpr.2011.07.003

Hofmann, S. G., Petrocchi, N., Steinberg, J., Lin, M., Arimitsu, K., Kind, S., Mendes, A., \& Stangier, U. (2015). Loving-kindness meditation to target affect in mood disorders: a proof-of-concept study. Evidence-Based Complementary and Alternative Medicine, 2015. https://doi.org/10.1155/2015/269126
Hofmann, S. G., Sawyer, A. T., Witt, A. A., \& Oh, D. (2010). The effect of mindfulness-based therapy on anxiety and depression: A meta-analytic review. Journal of Consulting and Clinical Psychology, 78, 169-183. https://doi.org/10.1037/a0018555

Hutcherson, C. A., Seppala, E. M., \& Gross, J. J. (2008). Loving-kindness meditation increases social connectedness. Emotion, 8, 720-724. https:// doi.org/10.1037/a0013237

Jacobsen, P. B., \& Jim, H. S. (2008). Psychosocial interventions for anxiety and depression in adult cancer patients: achievements and challenges. CA: A Cancer Journal for Clinicians, 58, 214-230. https://doi.org/10.3322/CA.2008.0003

Keng, S. L., Smoski, M. J., \& Robins, C. J. (2011). Effects of mindfulness on psychological health: A review of empirical studies. Clinical Psychology Review, 31, 1041-1056. https://doi.org/10.1016/j.cpr.2011.04.006

Kim, Y. H., Kim, H. J., Do Ahn, S., Seo, Y. J., \& Kim, S. H. (2013). Effects of meditation on anxiety, depression, fatigue, and quality of life of women undergoing radiation therapy for breast cancer. Complementary Therapies in Medicine, 21, 379-387. https://doi.org/10.1016/j.ctim.2013.06.005

Klimecki, O. M., Leiberg, S., Lamm, C., \& Singer, T. (2012). Functional neural plasticity and associated changes in positive affect after compassion training. Cerebral Cortex, 23, 1552-1561. https://doi. org/10.1093/cercor/bhs142

LePera, N. (2011). Relationships between boredom proneness, mindfulness, anxiety, depression, and substance use. The New School Psychology Bulletin, 8, 15-25.

Leppma, M., \& Young, M. E. (2016). Loving-Kindness Meditation and Empathy: A Wellness Group Intervention for Counseling Students. Journal of Counseling \& Development, 94, 297-305. https://doi. org/10.1002/jcad.12086

Lozada, M., D’Adamo, P., \& Fuentes, M. A. (2011). Beneficial effects of human altruism. Journal of Theoretical Biology, 289, 12-16. https://doi.org/10.1016/ j.jtbi.2011.08.016

Lutz, A., Slagter, H. A., Rawlings, N. B., Francis, A. D., Greischar, L. L., \& Davidson, R. J. (2009). Mental training enhances attentional stability: neural and behavioral evidence. Journal of Neuroscience, 29, 13418-13427. https://doi.org/10.1523/JNEUROSCI.1614-09.2009

Marteau, T. M., \& Bekker, H. (1992). The development of a six-item short-form of the state scale of the Spielberger State-Trait Anxiety Inventory (STAI). British Journal of Clinical Psychology, 31, 301-306. https://doi.org/10.1111/j.2044-8260.1992.tb00997.x

Mascaro, J. S., Rilling, J. K., Negi, L. T., \& Raison, C. L. (2013). Compassion meditation enhances empathic accuracy and related neural activity. Social Cognitive and Affective Neuroscience, 8, 48-55. https:// doi.org/10.1093/scan/nss095 
May, C. J., Weyker, J. R., Spengel, S. K., Finkler, L. J., \& Hendrix, S. E. (2014). Tracking longitudinal changes in affect and mindfulness caused by concentration and loving-kindness meditation with hierarchical linear modeling. Mindfulness, 5, 249258. https://doi.org/10.1007/s12671-012-0172-8

McClintock, A. S., \& Anderson, T. (2013). The application of mindfulness for interpersonal dependency: effects of a brief intervention. Mindfulness, 6, 1-10. https://doi.org/10.1007/s12671-013-0253-3

Nilsson, H. (2016). Socioexistential mindfulness: Bringing empathy and compassion into health care practice. Spirituality in Clinical Practice, 3, 22-31. https://doi.org/10.1037/scp0000092

Pekrun, R., Goetz, T., Daniels, L. M., Stupnisky, R. H., \& Perry, R. P. (2010). Boredom in achievement settings: Exploring control-value antecedents and performance outcomes of a neglected emotion. Journal of Educational Psychology, 102, 531-549. https://doi.org/10.1037/a0019243

Rachlin, H., \& Locey, M. (2011). A behavioral analysis of altruism. Behavioural Processes, 87, 25-33. https://doi.org/10.1016/j.beproc.2010.12.004

Rushton, J. P., Chrisjohn, R. D., \& Fekken, G. C. (1981). The altruistic personality and the self-report altruism scale. Personality and Individual Differences, 2, 293302. https://doi.org/10.1016/0191-8869(81)90084-2

Shapiro, S. L., Brown, K. W., \& Biegel, G. M. (2007). Teaching self-care to caregivers: Effects of mindfulness-based stress reduction on the mental health of therapists in training. Training and Education in Professional Psychology, 1, 105-115. https://doi.org/10.1037/1931-3918.1.2.105

Song, Y., \& Lindquist, R. (2015). Effects of mindfulness-based stress reduction on depression, anxiety, stress and mindfulness in Korean nursing students. Nurse Education Today, 35, 86-90. https:// doi.org/10.1016/j.nedt.2014.06.010

Tanay, G., \& Bernstein, A. (2013). State Mindfulness Scale (SMS): development and initial validation. Psychological Assessment, 25, 1286-1299. https:// doi.org/10.1037/a0034044

Tirch, D. D. (2010). Mindfulness as a context for the cultivation of compassion. International Journal of Cognitive Therapy, 3, 113-123. https://doi. org/10.1521/ijct.2010.3.2.113

van den Hurk, P. A., Wingens, T., Giommi, F., Barendregt, H. P., Speckens, A. E., \& van Schie, H. T. (2011). On the relationship between the practice of mindfulness meditation and personality - an exploratory analysis of the mediating role of mindfulness skills. Mindfulness, 2, 194-200. https://doi. org/10.1007/s12671-011-0060-7

Visser, M. S., \& Roelofs, M. R. (2011). Heterogeneous preferences for altruism: gender and personality, social status, giving and taking. Experimental Economics, 14, 490-506. https://doi.org/10.1007/ s10683-011-9278-4
Wahbeh, H., Lane, J. B., Goodrich, E., Miller, M. \& Oken, B. S. (2014). One-on-one mindfulness meditation trainings in a research setting. Mindfulness, 5, 88-99. https://doi.org/10.1007/s12671-012-0155-9

Wallmark, E., Safarzadeh, K., Daukantaite, D., \& Maddux, R. E. (2013). Promoting altruism through meditation: an 8-week randomized controlled pilot study. Mindfulness, 4, 223-234. https://doi.org/10.1007/ s12671-012-0115-4

Weng, H. Y., Fox, A. S., Shackman, A. J., Stodola, D. E., Caldwell, J. Z., Olson, M. C., Rogers, G. M., \& Davidson, R. J. (2013). Compassion training alters altruism and neural responses to suffering. Psychological Science, 24, 1171-1180. https://doi. org/10.1177/0956797612469537

Wittmann, M., \& Paulus, M. P. (2008). Decision making, impulsivity and time perception. Trends in Cognitive Sciences, 12, 7-12. https://doi.org/10.1016/j. tics.2007.10.004

Würtzen, H., Dalton, S. O., Elsass, P., Sumbundu, A. D., Steding-Jensen, M., Karlsen, R. V., Andersen, K. K., Flyger, H. L., Pedersen, A. E., \& Johansen, C. (2013). Mindfulness significantly reduces self-reported levels of anxiety and depression: results of a randomised controlled trial among 336 Danish women treated for stage I-III breast cancer. European Journal of Cancer, 49, 1365-1373. https://doi. org/10.1016/j.ejca.2012.10.030

Zakay, D. (2014). Psychological time as information: the case of boredom. Frontiers in Psychology, 5, 1-5. https://doi.org/10.3389/fpsyg.2014.00917

Zeidan, F., Johnson, S. K., Gordon, N. S., \& Goolkasian, P. (2010). Effects of brief and sham mindfulness meditation on mood and cardiovascular variables. The Journal of Alternative and Complementary Medicine, 16, 867-873. https://doi.org/10.1089/acm. 2009.0321 